\title{
INVESTIGACIÓN/RESEARCH
}

Recibido: 24/09/2013-----Aceptado: 21/10/2013-----Publicado: 15/03/2014

\section{SOCIOLOGÍA DE LA COMUNICACIÓN II: AUTORES, INVESTIGACIONES Y TEORÍAS}

Beatriz Peña-Acuña': Universidad Católica San Antonio. Murcia, España. bpena@ucam.edu

\section{RESUMEN:}

Este artículo pretende ofrecer una cronología de autores y teorías de modo sistemático desde los años 80 hasta el año 2000 teniendo en vista de la acogida on-line que ha tenido desde 2002 un primer artículo con la cronología de los años 30 a los 80 en una publicación anterior publicada en la Revista de Comunicación de la SEECI (Peña, 2002). Para realizar esta cronología, se ha realizado una revisión de la literatura pertinente, en concreto de manuales de teorías de la Sociología de la Comunicación. Mediante este texto pretendemos que el lector encuentre un instrumento ventajoso para adentrarse en el estudio de la Sociología de la Comunicación y, en concreto, en los estudios sobre los efectos de los medios de comunicación sobre el receptor.

PALABRAS CLAVE: Teorías sociológicas - Efectos - Receptor - Interaccionismo Simbólico - Posmodernismo

\footnotetext{
${ }^{1}$ Beatriz Peña Acuña: Profesor contratado doctor de la Universidad Católica de San Antonio en Murcia, España. Investigadora principal del grupo de investigación "Desarrollo personal". Correo: bpena@ucam.edu
} 


\section{SOCIOLOGY OF COMMUNICATION II: AUTHORS AND THEORIES}

\section{ABSTRACT:}

This article offers a chronology of authors and theories in a systematic way from 1980 to 2000. Through this text we want the reader to find a useful tool to enter the study of the Sociology of Communication and, specifically, studies on the effects of Media on the receiver. To place this timeline, there has been a review of the relevant literature, manuals specific theories of Sociology of Communication. Through this text we intend the reader to find a bargain to go into the study of Communication Sociology instrument and, in particular, studies on the effects of media on the reception.

KEY WORDS: Sociological theories - Effects - Receiver - Symbolic interactionism Postmodernism.

\section{INTRODUCCIÓN}

Esta disertación se compone de varias partes, una primera metodológica en la que se definen los objetivos y la metodología; una segunda a partir del epígrafe siguiente titulado Resultados. En este epígrafe se respeta un orden cronológico para presentar autores y corrientes. En la primera parte se explican los estudios de los años ochenta con referencia al emisor. En la segunda parte se explica el tercer periodo de estudio de los efectos desde los años 70. Finalmente en la tercera, se expone los estudios de los 90 en el panorama de la Sociología de la Comunicación. Por último, se expone la discusión acerca de esta cuestión desde un punto de vista cenital.

\section{OBJETIVOS}

Este artículo pretende ofrecer una cronología de autores y teorías de modo sistemático desde los años 80 hasta el año 2000 teniendo en vista de la acogida on-line que ha tenido desde 2002 un primer artículo con la cronología de los años 30 a los 80 en una publicación anterior publicada en la Revista de Comunicación de la SEECI (Peña, 2002).

Dado que es difícil encontrar manuales y artículos que muestren de forma ordenada la cronología de autores y teorías acerca de la Sociología de la Comunicación, pretendemos mediante este texto que el lector encuentre un instrumento ventajoso para adentrarse en el estudio de esta disciplina y, en concreto, en los estudios sobre los efectos de los medios de comunicación sobre el receptor.

\section{METODOLOGÍA}

Para realizar esta cronología, se ha realizado una revisión de la literatura pertinente, en concreto de manuales de teorías de la Sociología de la Comunicación y se han dispuesto los autores y teorías de modo sistemático y cronológico por décadas. 


\section{RESULTADOS}

\subsection{Estudios de los años ochenta sobre el emisor.}

Aparece la teoría del newsmaking, la sociolingüística y la etnolingüística, y el análisis del discurso informativo. Se dan estudios interdisciplinares de los emisores y los mensajes. Aparece Erving Goffman, sociólogo alemán, continuador del interaccionismo simbólico. Este autor es interesante por la formulación del análisis de la dramaturgia en relación al aprendizaje social (1977), reveladora del comportamiento social en cuanto al aprendizaje de los roles. Asimismo se dan otras corrientes como la sociosemiótica, las teorías profesionales de Epstein y la teoría de la producción de la noticia.

Gerbner en 1980 propone a los Mass Media como agente de socialización. Se trata de la Teoría del cultivo o teoría de los efectos cultivados: matizó más la fuerza del impacto de la comunicación. Sin embargo, Wolf valora más la acumulación, el proceso de la influencia (1994).

Noelle-Neuman, europea, cree en la efectividad o el cambio de las conductas, actitudes o formas de pensar de los sujetos porque forman otras nuevas. Estudia el efecto diverso del mismo mensaje y da estas variantes (nivel educativo, personalidad, ambiente social, grado de convicción en actitud, circunstancias externas). Se ha visto que los dos primeros factores filtran los efectos (Huesmann, Lagerspetz y Eron 1984; Bushman y Geen, 1990).

Tuchman (1980) trabaja con conceptos fenomenológicos europeos como los que expone Shutz e interaccionistas americanos como expone Goffman. Philips estudia la efectividad puesto que influye el ambiente social y el grado de convicción que el sujeto tiene sobre un hecho. Se realiza una crítica a la industria de la conciencia por Stormbom y Enzensberger (1972). Navarro Valls estudia el papel educativo de la publicidad que ayuda a fijar actitudes y juicios de valor (1971). Se da una moderna crítica utópica expone el papel positivo y formador de los medios en autores como Ahmavaara (1969).

Surge el construccionismo de Berguer y Luckmann (1983). Estos formulan que un individuo no nace como miembro de una sociedad, sino que tiene simplemente una predisposición hacia la sociabilidad. El punto de partida es la internalización: mediante la socialización no sólo se comprende el mundo, sino que también se convierte en el mundo de uno mismo. La socialización jamás se termina y los contenidos que la misma internaliza enfrentan continuas amenazas a su realidad objetiva (Rodrigo Alsina, 2001). Como señala Krieg, el sentido de esos medios es crear conjuntamente ámbitos consensuales dentro de los cuales es posible una coordinación de las acciones de los individuos. Por lo tanto, la realidad es una construcción social que a su vez permite y constituye a la sociedad. Por lo tanto los medios tienen la función de crear esa realidad construyéndola mediante la observación de la sociedad y difundiéndola en ella (Rodrigo Alsina, 2001). 
La corriente de la Etnometodología se centra en el estudio de la acción a la que conciben en tanto implica y entraña un actor reflexivo. Según Garfinkel, el orden social se deriva al menos parcialmente de la reflexividad (término que debe entenderse como el proceso en el que estamos todos implicados para crear realidad social mediante nuestros pensamientos y nuestras acciones) de las personas. Rechazan la idea de que el orden se deriva meramente de la conformidad de las normas. Es la conciencia del actor de sus opciones, así como su capacidad de anticipar cómo van a reaccionar los otros a lo que ellos dicen y hacen, lo que dispone el orden en el mundo cotidiano.

En la etnometodología se estudia de qué modo "las personas crean y mantienen sus concepciones de un mundo real a través de sus interacciones sociales" (Rodrigo Alsina, 2001, 181). Según Cicourel "la reciprocidad y los procedimientos normales implican que los miembros de una comunidad interiorizan los aspectos fundamentales de su cultura común- supuestamente la misma para todos- para facilitar las cosas" (Rodrigo Alsina, 2001: 181). Giddens le critica que no tiene en cuenta que las normas sociales son "susceptibles de interpretación diferencial. De hecho una sociedad dividida en clases o intereses diferentes es inevitable esta interpretación diferencial". (Rodrigo, 2001: 182).

En 1980 Striker intenta dar un enfoque macro con su teoría del rol. Abrigaba la esperanza de incorporar, en última instancia, factores estructurales tales como la clase, el status o el poder, como variables que constriñen la interacción, pero no deseaba que el interaccionismo simbólico analizara las interrelaciones entre las variables estructurales.

Habermas y Luhmann se estiman como los artífices de la posmodernidad. Habermas se sitúa en la Escuela de Frankfurt en 1929. Su obra constituye un ataque radical a la idea de que el positivismo la ciencia y la investigación modernas son objetivas. Este autor opina que la ciencia y la tecnología están más bien regidas por valores e intereses que a veces contradice la búsqueda desinteresada de la verdad. Habermas sostiene que la sociedad tecnológica y el consiguiente aumento de la burocracia han servido, entre otras cosas, para perpetuar las instituciones del Estado y despolitizar a los ciudadanos. De esta forma la razón y la ciencia se han convertido en herramientas de dominación más que de emancipación.

La principal contribución a la filosofía de Habermas fue una teoría sobre la racionalidad, la habilidad de pensar de forma lógica y analítica. Este autor imagina un futuro en el que la razón y el conocimiento trabajen en pro de una sociedad mejor. En ese futuro, la comunicación humana no debería estar sujeta a la dominación del Estado y los ciudadanos racionales deberían poder actuar en la sociedad de forma libre en el ámbito político.

En 1965 Luhmann se traslada a Alemania desarrolla el funcionalismo sistémico y alentará la publicística funcional.

El referente más inmediato del Posmodernismo, frente al que toman partido los 
posmodernistas es la revista "Screen", dedicada sobre todo al estudio del cine, de obediencia a Lacan, que formula que nos imaginamos que somos la fuente de los significados y la identidad, pero en realidad estamos sujetos a las diferencias de lenguaje. Los teóricos de Screen analizan la película como un discurso, sin tener en cuenta que "lo popular es un campo de posible contestación o contradicción" (Ariño, 1997: 186).

Estos autores se dedican a realizar estudios sobre cómo afectan los medios en el individuo y luego este sobre la sociedad: hacen un estudio sobre los impactos (más que una crítica a los contenidos). Benneth mantiene que los medios mantienen el orden social (1988). Liebert, Sprafkin estudian la estimulación de conductas agresivas en niños y puesta en peligro de la salud de todo un colectivo (1988). Postman ve incompatible la lectura y el aprendizaje con la TV porque estimula otra atención, la de diversión (1985). Se afirma en el terreno de la política con la utilización de la televisión según Wilcox, Ault y Agee en 1995.

En referencia a la Teoría de la socialización, Maccoby (1964) expone que todos los niños al mismo tiempo que se entretienen con la TV, absorben información que contribuye a conformar las ideas y actitudes que determinarán su comportamiento futuro. Meyrowitz apoya la teoría de la socialización y argumenta que los niños son socializados dentro de las reglas de los adultos a una edad más temprana de lo que era habitual hace años, debido a la influencia de la televisión. Van Eyra en 1990 estudia más las condiciones o circunstancias personales y medioambientales. Este autor argumenta que los efectos son especialmente significativos cuando el objetivo es ver la pantalla por diversión y cuando perciben el contenido como real. Van Eyra atribuye tales efectos a una falta de pensamiento o juicio crítico durante el momento de la recepción. También hay mayor socialización cuando ven con frecuencia la TV y tienen poca información alternativa posible. También Rosengren 1992 piensa que los Media y en especial la TV es un agente de socialización extremadamente importante. La percepción de los niños de la realidad cultural en la que viven es, en parte, una creación de los medios de comunicación. Zoohori 1988 encontró que los niños extranjeros encontraban la TV más interesante, pasaban más tiempo viéndola, se identificaban con los personajes que aparecían en la pantalla y utilizaban este medio como aprendizaje con más frecuencia de lo que hacían los niños nativos americanos.

La crítica a la teoría de la socialización concreta poco y no considera las tendencias históricas y sociales del mundo actual. Kubey afirma en 1992 que no discierne qué peso tiene la familia y qué peso la televisión; que también depende de cada niño. Kubey sostiene la teoría de usos y gratificaciones, y el receptor activo: dice que pasar muchas horas delante del TV es más un efecto que una causa de factores del humor, de la personalidad o de los dos a la vez.

Dentro de la teoría de la socialización también están Heath y Bryant (1992). Ponen el énfasis en la circunstancia de una prolongada exposición a los contenidos TV enseña a los receptores el mundo, próximo y lejano, e indica el comportamiento que se considera adecuado en el mismo. 
La teoría de los usos y las gratificaciones comienza en los años 40 cuando se comprenden más las consecuencias de las diferencias individuales y la diferenciación social: se considera al receptor como activo, ya que selecciona los mensajes y el contenido preferido, es más consciente. La idea central es que los efectos dependen en parte de los usos que la audiencia hace de la misma y de las gratificaciones que los sujetos reciben. La elección viene determinada por el grado o tipo de entretenimiento y /o información que ofrece dicho medio; también como refugio fantástico, como compañía, como sustituto de otra actividad más desagradable. Palmgreen (1984) sostiene que los sujetos ven programas que de verdad les disgustan sobremanera simplemente para tener algún tema de conversación y sentirse menos solos. Winick (1988) habla de seis funciones: tener información, relax y entretenimiento, conversación, motivos sociales, estar al día y compañía. Kubey (1986) otra razón es la sensación de escape consecuencia de la intervención de dos variables: humor y personalidad.

Katz, Blumler y Gurevitch proponen varios factores acerca de este proceso. Entre estos:

- el público es activo y se acerca a los medios para lograr ciertos objetivos

- cada miembro de la audiencia tiene la iniciativa de vincular la gratificación de una necesidad con la elección de un medio. Ello supone una fuerte limitación a la posibilidad de efectos directos en la línea de las pretensiones exactas de los emisores

- hay una competencia entre los Mass Media y otras fuentes a la hora de procurar gratificar a los sujetos

- los individuos poseen la suficiente capacidad para reconocer sus motivos de uso o sus necesidades

- los juicios de valor acerca de la calidad cultural e influencia nociva o no de los contenidos de los medios resultan inválidos si se renunciara a conocer lo que declaran al respecto los componentes del público.

Conway y Rubin (1991) añaden que la atracción hacia determinados programas incrementa las posibilidades de que éstos produzcan efectos en sus receptores.

La crítica a esta teoría se plantea por parte de McQuail en 1979. Este autor dice que este modelo no se puede aplicar a los niños; también le ocurre a Dader (1992), pues estima que se produce una vaguedad de conceptos; son demasiado individualistas y psicologistas, se produce una carencia de una profundización crítica respecto a la influencia social de los medios y el método de investigación idóneo para un análisis conservador y dudas sobre si los medios no crearán las propias necesidades que satisfacen; asimismo existen dudas de que los entrevistados revelen sus auténticas motivaciones, o dudas de que la audiencia sea en realidad activa.

Acerca de la teoría social del aprendizaje el representante es Bandura psicólogo-social (1963) que procede de los psicólogos behaviouristas o conductistas y de su modelo de estímulo-respuesta. Este defiende con positividad que la televisión se convierte en una fuente de aprendizaje mediante la observación de los modelos y conductas expuestas en la pantalla. Jeffres en 1986 da estos pasos sobre el aprendizaje conductual: poner atención, recordar la conducta o repetición cognitiva, poseer la habilidad cognitiva y la 
motivación suficiente para practicar la conducta; además indica que la motivación se mantiene mediante el reforzamiento interno o externo. Otros estudios estudian otras variables para conocer hasta qué punto influyen en el proceso de imitación y cuáles tiene más posibilidades de ser imitadas: la similitud entre modelo y receptor, credibilidad del modelo, contexto del receptor, semejanzas de vida entre modelo y vida del receptor, estado emocional del receptor, y percepción de la realidad que ve en la TV.

A este autor lo critica Harris, pero más adelante reconoce el efecto modelaje producido por la TV (Huesman ,Lagerspetz y Eron 1984, Joy, Kimballl y Zabrack 1986).

\subsection{Tercer periodo de estudios de los efectos (1970-1999).}

Aparece la teoría del cultivo y la teoría de los efectos selectivos basados en diferencias individuales. Gerbner de la Escuela de Comunicación de la Universidad de Pensilvania, destaca que la visión del mundo de los sujetos que pasan muchas horas delante del televisor es, con toda probabilidad, la visión del mundo que presenta la enfoque del mundo que presenta este medio. El entorno televisivo no cultiva sólo sistemas de creencias, sino que produce también actitudes emotivas correspondientes a los sistemas de creencias.

Otros autores como Rubin, Perse y Taylor, (1988) dicen que los grandes consumidores de televisión manifiestan una amplia gama de estados emocionales y cognitivos que incluyen una acentuada falta de autoestima y una mayor sensibilidad hacia los problemas racionales, perciben a los ancianos como más marginales, tienen unos niveles de ansiedad más elevados y demuestran una mayor insatisfacción respecto al estilo de vida. Viene a demostrar que la exposición continua a los contenidos televisivos configura a largo plazo la visión del mundo de los receptores y la realidad social de los individuos.

Una de las aportaciones de la teoría del cultivo es la mainstreaming, la homogeneización de las percepciones sobre la realidad social de los individuos dentro de una corriente principal. Es un proceso de construcción por el cual los receptores aprenden hechos acerca del mundo que les rodea mediante la observación del mundo de la TV. La memoria almacena todo lo que ve en TV (Shapiro, 1991); además las personas utilizan la información almacenada para formular creencias acerca del mundo real (Potter, 1988). Cuando este mundo construido y el mundo real tienen un alto grado de correlación se da el estado de resonancia o prolongación de la visión del mundo, con lo cual el efecto de la TV, es incluso más fuerte. Esto viene a significar que existe cierta congruencia entre las representaciones de los media y las experiencias personales de los sujetos.

Los detractores de este planteamiento son Hughes, Perse y Wober, pues el control de ciertas variables socio-demográficas e individuales tienden a reducir o eliminar los efectos de cultivo. Este tipo de efectos tiene como principales receptores a personas de más edad o personas que viven en ámbito rural. En ambos casos, el contacto con 
la realidad social es más distante. Se tiene en consideración tanto los medios (tamaño, estilo, estructura y organización) como las características de los sujetos. Los efectos son diversos y dependen de distintas variables. La edad, el sexo, la clase social y las características personales del sujeto receptor también influyen. Los medios de comunicación refuerzan conocimientos y actitudes previas, pero muy difícilmente las modifican. Las variables socio demográficas, el mensaje y el contexto determinan los efectos.

Felsenthal (1974) dice que se evitan mensajes según sus predisposiciones; pueden llegar a cubrir aquello sobre lo que no se tenía opinión (Ulloth, Klinge y Eells, 1983). Se recogen las conclusiones sobre los experimentos (recogidos por Hearold en 1986 sobre la conducta social); en cuanto a la violencia (Philips, 1986) afirman la importancia de los medios en la sociedad actual, el papel y los efectos. Se realizan estudios sobre el tamaño y estructura al estilo u organización (Triplett, 1991).

Acerca de la teoría de la Agenda-Setters, teoría de efecto cognitivo que mantiene que se producen efectos poderosos de los medios lleva a determinar lo que la audiencia percibe como importante, e incluso, sobre qué deben pensar (Thayer, 1988) da aquello sobre lo que deben pensar (McCombs y Shaw, 1972), pero no qué posición tomar. Puntúan sobre la habilidad de los Mass Media para estructurar las opiniones de la audiencia y producir cambios entre las opiniones ya existentes. Coinciden las teorías de la agenda setting americanas con las teorías luhmanianas y las hipótesis cognitivistas de Noelle Neumann en Europa.

Heath y Bryant (1992) establece las prioridades que orienta la opinión pública, determina la percepción de dichos temas y el establecimiento de su importancia.

Los primeros estudios (1988 Rogers y Dearing) estuvieron más preocupados por los efectos de los medios de comunicación respecto a lo que los individuos pensaban, por ejemplo, en términos de actitudes.

McQuail (1987) afirma que el proceso trata con 3 agendas:

-la agenda de los políticos u otros grupos de interés

-la agenda de los medios de comunicación, la cual está afectada y estructurada por los nuevos valores y preferencias de la audiencia

-la agenda pública supuestamente afectada por la agenda de los medios de comunicación y por la de los políticos

Las relaciones que se producen en este modelo son las siguientes, a saber, la agenda de los Mass Media ejerce su influencia tanto en la agenda pública como en la agenda política; la agenda pública influye sobre la agenda política y a su vez la agenda política afecta a la agenda de los medios de comunicación.

Parenti (1986) explica que refuerzan conocimientos, actitudes y/o conductas, en lugar de introducir nuevos elementos. Dorr (1980) tiene que ver el efecto con la peculiaridad personal (sexo, edad, clase social) del sujeto receptor. 
Sobre la Teoría de los efectos selectivos basados en las diferencias individuales Sprafkin, Gadow y Abelman, (1992) intentan descubrir otras variables interactivas que median o moderan los efectos -las variables socio demográficas, las propiedades del mensaje o el contexto de la recepción-. Smith (1995) expone cuatro combinaciones: los cambios en los individuos pueden no tener impacto a nivel social. Casos en los que las conductas individuales son hechos aislados, que no interfieren en el desarrollo social; los cambios en los individuos son seguidos por mudanzas sociales; los cambios a nivel social pueden estimular transformaciones en el individuo; los cambios a nivel social pueden no implicar reformas en los individuos.

Entre las teorías que no sostienen los efectos se encuentra:

McGuire (1986) expone ciertos modelos de efectos:

- Conductuales: cambio de las conductas de los sujetos receptores como consecuencia de la exposición a la TV.

- En actitudes: cambio o reforzamiento de actitudes de los sujetos tras la exposición a TV.

- Efectos cognitivos: cambio en la forma de pensar o percepción de realidades.

En el modelo de Ball-Rockeach (1982) habría que distinguir tres tipos de efectos, los efectos cognitivos, afectivos y conductuales.

- los efectos cognitivos estos autores hacen referencia a la posible ambigüedad de la información y a las actitudes, creencias y valores de las audiencias.

- los procesos afectivos se refieren a los sentimientos y a las emociones; concretándose en la pérdida de sensibilidad, el miedo y la ansiedad, y la moral y la alineación. De los numerosos efectos sobre la conducta sólo consideran la activación y la desactivación. Es difícil determinar los efectos de los Media ya que se produce un consumo multimedia que complica la determinación de la influencia de cada medio (Rodrigo Alsina, 1995).

\subsection{Estudios de los años noventa.}

La síntesis teórica se puede enumerar del siguiente modo con la aparición de:

- Las teorías culturológicas de Morin y socio semióticas junto al funcionalismo crítico de Mattelart promueven análisis socioculturales en Iberoamérica

- Neo funcionalismo: Estética de la Recepción, consumo diferencial y nuevas formas de recepción. Alexander, Munich, Sciulli.

- La teoría de la Posmodernidad con representantes como Baudrillard, Lyotard y Jameson

- El debate de la sociedad de masas

- Las teorías socio dinámicas

- La fenomenología social con la representación de Shutz

- Las teorías críticas

- La antropología cultural con Carey como exponente (1981)

- Socio semiótica (por ejemplo, Miquel Rodrigo Alsina)

Morin nace en 1921 en París. En 1950 es admitido en el CNRS (Centre National de la Recherche Scientifique) En 1959 fundó con Friedman y Barthes el Centro de Estudios 
de Comunicación de Masas y publicó la revista Communication, y luego Arguments. Se interesó por las relaciones entre lo real lo imaginario en la cultura de masa difundida por los medios de comunicación. Intentó explicar el fenómeno del rumor estudiando la propagación de una información vaga, imprecisa y consolidada basada en el antisemitismo, en personas más o menos crédulas. Muy pronto se convirtió en el defensor de una sociología del presente llamada "evidencial". Inauguró un nuevo campo de investigaciones; conociendo la complejidad de los sistemas, lejos de buscar la unidad de las ciencias, destacó la importancia de la noción de desorden. Dio con el concepto de ecosistema con el que intenta explicar la diversidad real surgida de la auto-organización, la selección y la adaptación del mundo humano. En Ciencia con consciencia profundizó en el concepto de la complejidad.

Se realizan estudios culturales desde el punto de vista consensual (consensuales). Los medios de comunicación serán vistos como instrumentos para establecer y mantener una armoniosa integración de los valores y los significados en la sociedad.

L. Carey investiga desde la antropología cultural sobre la comunicación de masas y los estudios culturales. La comunicación es entendida como ritual, como comunión. Los medios de comunicación serían parte del esfuerzo de toda una sociedad para dar sentido a las situaciones y para crear una especie de interpretación aceptable de los significados. Se pone el acento en el proceso de construcción de significados. Se tiende a ver a los Mass Media como un fórum, un espacio público, donde los significados culturales son presentados para ser reexaminados y debatidos por distintos sectores culturales (Rodrigo Alsina, 1995).

Se producen estudios culturales de la cultura popular por parte de Jesús Martín Barbero, en Latinoamérica (Rodrigo Alsina, 1995). Éste plantea cómo las comunidades se apropian de algunos elementos de los medios de comunicación para construir su propia cultura. La construcción del significado por la audiencia es el resultado de la confrontación y la negociación de diferentes actores que representan la lógica de las industrias culturales, la lógica de la vida cotidiana, la lógica de los movimientos sociales y muchas otras lógicas. Al estudiar los medios desde esta nueva perspectiva se pueden apreciar las interacciones entre las lógicas de producción y de la recepción. A estos procesos de interacción, de lucha, de resistencia y transformación Martín Barbero los denomina mediaciones. G. Orozco Gómez (1993) establece cuatro grupos de mediaciones:

- mediación individual parte del sujeto cognoscitivo y emotivo

- la mediación situacional

- la mediación institucional

- la mediación vídeo-tecnológica.

\section{DISCUSIÓN}

A lo largo de los años 80 hasta el 2000 se enriquece el discurso acerca de los efectos de los Medios y de la recepción con investigaciones más especializadas cada vez. Los autores, investigaciones y teorías que presentan en algunos casos sincretismo en el marco de la Sociología de la Comunicación discurre entre debates entre los autores 
descubriendo, sin embargo, cada vez más el apenas abarcable y complejo panorama del proceso humano de comunicar y la riqueza de variables que lo afectan tanto sociales como psicológicas, etc.

\section{REFERENCIAS}

ALADRO VICO, E. (1999): Teoría de la Información y la Comunicación Efectiva. Madrid: Fragua.

ARIÑO, A. (1997): Las Audiencias Activas. Madrid: Ariel.

BIAGI, S. (1999): Impacto de los medios. México: International Thompson Editores.

COROMINAS I CASALS, A. (1999): Modelos y medios de comunicación de masas. Bilbao: Descleé de Brouwer, Colección Aprender a ser.

GOFFMAN, E. (1997): La presentación de la persona en la vida cotidiana. Buenos Aires: Amorrutu Editores.

HOVEYDA, F. (2000): The hidden meaning of Communications: cinema, books and television in the age of computers. Westport: Praeger Publishers.

LLUL, J. (1997): Medios, comunicación, cultura. Buenos Aires: Amorrutu editores.

PEÑA-ACUÑA, B. (2002, noviembre): Cronología de la Sociología de la Comunicación. año $V$ no 9, págs: 1-13. Revista de Comunicación de la SEECI. Recuperado el 29 de julio de 2013, de http://dialnet.unirioja.es/servlet/articulo?codigo=4158982

REDONDO, E. (2000): Educación y comunicación. Barcelona: Ariel.

RODRIGO ALSINA, M. (1995): Los Modelos De La Comunicación. (2a edic.) Madrid: Tecnos.

RODRIGO ALSINA, M. (2001): Teorías De La Comunicación: Ámbitos, Métodos y Perspectivas. Barcelona: Servei de Publicacions de la Universitat Autonoma de Barcelona.

SORLIN, P. (1974): Sociología del cine: la apertura para la historia del mañana. México: Fondo de Cultura Económica.

STAM, R. (2001): Teorías del Cine. Barcelona: Paidós.

\section{Beatriz Peña Acuña}

Ha cursado estudios interdisciplinares de Filología Española, Estudios Humanísticos y Periodismo. Premio Extraordinario de Doctorado en la Universidad de Alicante. Está habilitada como profesor contratado doctor y Universidad Privada por ANECA. Es 
directora del grupo de investigación internacional e interdisciplinar llamado "Desarrollo personal" en la UCAM. Actualmente imparte clases en UCAM en Grados de Magisterio y "Dirección de comunicación y habilidades directivas" en ADE. Imparte también clases a dos Másters y en inglés a Posgrado. Actualmente dirige la colección "Desarrollo Personal" en la editorial Vision Libros. Ha publicado varios libros y artículos en revistas de impacto nacionales e internacionales. 